\title{
Which outcomes do women expect to achieve after undergoing induced abortion
}

\author{
Sedigheh Nouhjah ${ }^{1}$, Fereshteh Zamani-Alavijeh ${ }^{1,2}$, Akbar Babaei Heydarabadi ${ }^{3}$, Maedeh Hozaili ${ }^{4}$
}

\author{
${ }^{1}$ Social Determinants of Health Research Center, School of Health, Ahvaz Jundishapur university of Medical \\ Sciences, Iran \\ ${ }^{2}$ Ph.D. in Health Education and Promotion, Associate Professor, Department of Health Education, Faculty of \\ Health, Isfahan university of Medical Sciences, Isfahan, Iran \\ ${ }^{3}$ Ph.D. in Health Education and Promotion, Assistant Professor, Department of Public Health, Faculty of Health, \\ Ahvaz Jundishapur University of Medical Sciences, Ahvaz, Iran \\ ${ }^{4}$ Department of Public Health, Faculty of Health, Ahvaz Jundishapur University of Medical Sciences, Ahvaz, Iran
}

\section{Type of article: Original}

\begin{abstract}
Introduction: Unsafe abortion is one of the most important health problems in many countries. Because of legal and moral issues, abortion is one of the most sensitive decisions. The aim of this study was to understand women's expected gains from undergoing induced abortion.

Methods: To explain the factors leading to induced abortion, we collected the stories and experiences of a total of 21 people, including 18 women who underwent induced abortion in their most recent pregnancies, two women's health providers, and a companion of a mother who died after an induced abortion. This qualitative study was conducted in Imam Khomeini and Razi hospital of Ahvaz and also a number of health centers, from February to September 2014. To collect the required data, we used open and semi-structured deep interviews. Content analysis method was used to analyze the data.

Results: Three major themes emerged from the analysis of the collected data, which included the following: 1) Expected favorable health-related outcomes, 2) Expected favorable economic outcomes, and 3. Expected favorable outcomes in social level and family relationships.

Conclusion: The results of this study showed that the studied women, to achieve to desirable outcomes in areas of health, economic and social, have undergone induced abortion. Hence, to develop programs for the prevention of induced abortion it is necessary to consider the motivations of women to intentionally terminate a pregnancy.

Keywords: Induced abortion, Behavioral beliefs, Qualitative research
\end{abstract}

\section{Introduction}

Induced abortion has a history of twenty thousand years and occurs in all countries, regardless of racial, religious, social, and economic differences. Although induced abortion has been the topic of widespread public and political debate, the causes of induced abortion are the issues which have received less attention (1). About 46 million cases of induced abortions occur annually around the world, with more than half of the cases occurring in developing countries and they often occur in unsanitary conditions $(2,3)$. Each year, 21.6 million women experience unsafe abortions and 4700 women die for that reason (2). Induced abortions are usually carried out in non-standard conditions and are performed by people who lack the necessary information and skills $(4,5)$ and most of the victims have no information about the skills or capability of the people who perform abortions (6). Unsafe abortion, according to the World Health Organization, is the main cause of a quarter of maternal deaths during pregnancy and childbirth in developing countries (7). In addition to death, several other complications such as severe bleeding, infections and septic shock, uterine rupture and hysterectomy, infertility, kidney failure, embolism, and psychological disorders may occur in women undergoing abortion $(5,8)$. Women who have experienced induced

\section{Corresponding author:}

Associate Professor Dr. Fereshteh Zamani-Alavijeh, Department of Health Education, Faculty of Health, Isfahan university of Medical Sciences, Isfahan, Iran. Email: fe.zamani@gmail.com

Received: February 08, 2016, Accepted: May 08, 2016, Published: February 2017

iThenticate screening: May 08, 2016, English editing: September 01, 2016, Quality control: November 08, 2016 (C) 2017 The Authors. This is an open access article under the terms of the Creative Commons Attribution-NonCommercialNoDerivs License, which permits use and distribution in any medium, provided the original work is properly cited, the use is non-commercial and no modifications or adaptations are made. 
abortions in their recent cases of pregnancy are three times more at risk of suicide (9). It seems that legal restrictions on induced abortion have had no effect on the incidence of abortions. For example, the rate of induced abortions in Africa, a continent where induced abortion is illegal in most areas, is $29 \%$, while in Europe, where abortion is not illegal in most countries, it is $28 \%$. In addition, the lowest rates of abortion are reported in the western and northern Europe where there is the least restrictions on abortion (2). In other words, there may be some legislation to restrict abortion, but people who are determined to do it will undergo abortion in any way possible (10).

In order to observe the social norms and to protect oneself against social judgments, women usually try to keep their history of abortion confidential; however, there are some evidence-based and non-evidence-based statistical data about the cases of induced abortion in Iran. According to the only reliable source of data in the country, approximately 80 thousand cases of unsafe abortion occur in Iran annually (11). Based on the results of a study in Tehran, $84 \%$ of all cases of induced abortions were illegal (12). The results of an indirect estimation showed that the mean experience of induced abortions during pregnancy was 1.07 among Iranian women (13). According to the results of a study by Erfani and McQuillan, the overall rate of abortion in Iran was an estimated 0.26 for any married woman, in other words of every four women married, a woman experience induced abortion during her reproductive age (14). According to the results of a study which was conducted in eight hospitals in Isfahan, the prevalence of induced abortions was $12 \%$ (15). In addition, Nikpour et al. conducted a study to determine the frequency of induced abortion and its related factors in women who were referred to hospitals in the south of Tehran; the results of their study showed that $26.7 \%$ of the studied women underwent induced and illegal abortions (16). Obviously, as there is no access to the data about the illegal abortion centers and since women may fear the legal and social consequences of induced abortion, the actual prevalence of abortion is expected to be higher than the reported statistical data. In addition, the statistical data reported from many developing countries indicate a high incidence of induced abortions and illegal abortions; for instance, the overall prevalence of abortion in urban areas of Nigeria is $49.6 \%$, of which $82.2 \%$ of cases are induced abortions (17). Because of legal and religious concerns, abortion is one of the most private personal issues, and people are tended to hide and not report the cases of abortion; hence, conducting qualitative research may greatly help to collect data related to abortion. On the other hand, abortion and its various aspects has been the subject of widespread moral, religious, political, and legal debates in many countries, while in most cases no attention has been paid to the views of women who are victims of abortion. Because of the differences in cultural and social backgrounds, to understand complex phenomena such as abortion, it is necessary to make deep investigations without any presumption. To prevent Induced abortion and related high risk behaviors and outcomes, it is necessary to identify factors such as attitude influencing women's decisions and behavior to continue or terminate their pregnancy. Understanding these factors can significantly help to design future interventions. Attitude is one of the psychological factors influencing decision and every behavior. Attitude toward the behavior includes positive and negative assessments of a behavior (18). Behavioral beliefs result in positive or negative attitude about the continuation or termination of the pregnancy. According to Ajzen and Fishbein, behavioral beliefs are what the people expect about the outcomes of a specific behavior (19). Therefore, in this study behavioral beliefs are the outcomes which women expect to achieve after undergoing induced abortion. The results of some studies show that women's beliefs towards abortion are among the most important factors influencing their decision for abortion (20). For as much as according to the forensic report, in 2014 the highest abortion requests were respectively in the cities of Tehran, Mashhad and Ahvaz (21), and also given the importance of induced abortion and its impact on the lives of women, considering the high prevalence of induced abortion, and as there are a limited number of studies on this subject, this qualitative research study was designed to investigate and discover the outcomes which women expected to achieve after undergoing induced abortion.

\section{Material and Methods}

In this qualitative study, direct and indirect experiences of the participants were investigated and analyzed to explain the women's expected gains from undergoing induced abortion. The participants were selected via purposive sampling method. The eligible women were first introduced by midwives working in the health care centers. The participants who reported a history of abortion (without medical indication) in a recent pregnancy were deep interviewed until data saturation. Overall, a total of 21 deep interviews were conducted during February to September 2014. The interviews were performed in a relatively quiet location in Imam Khomeini and Razi hospital of Ahvaz and also a number of health centers. Each interview, depending on the content and conditions, lasted 30 to 90 minutes. Before the interviews, we recoded the demographic and personal characteristics of women and their husbands such as age, employment status of women and their spouses, education level and ethnicity of women and their spouses, and number of pregnancies. Questions were raised in a sequence, based on the answers of the interviewees. All interviews were conducted by a member of the research team. At the beginning of each interview, 
some questions were raised to make the interviewer more familiar with the participants, and also to create an intimate atmosphere. interviews were started with open questions, such as the following: "What was your expected outcome that motivated you to undergo induced abortion?" or "What outcomes did you expect when you underwent induced abortion?" Then to complete the themes, considering their earlier responses, more specific questions were asked. We tried to select participants from different groups in terms of education, occupation, and ethnicity. The participants were classified into two groups. The first group included key informants who had recent direct experience of induced abortions. The second group included general informants who had indirect experience and were somehow familiar with the participants from the first group (this group included two health care experts and a woman whose sister died due to the complication of induced abortion).

Interviews were recorded and some notes which described the moods and attitudes of participants, were taken. Then, the interviews were transcribed verbatim. To analyze the data, we used thematic analysis method. Immediately after each interview, the recorded audios were listened to, and the transcribes were read several times by all members of the research team; then every unit of meaning was extracted and the initial coding were carried out based on the analysis of the interviews with the participants. Then we made constant comparison and formed the subthemes based on the similarities and differences between initial codes; continuing the same process, the main themes and themes were determined. Transcribed interviews, the initial codes, subthemes, and themes were reviewed several times, and if necessary, the codes were revised, and previous themes were split or merged, and new themes and major themes were formed. To ensure trustworthiness of findings, we made an enduring and continuous contact with mothers and other participants (22). Part of the text and the initial codes were presented to the participants to check the consistency between the codes extracted by the researchers and the views stated by the participants (member check); using this method, we compared the interpretations of the researchers and the opinions of the participants. To check the scientific strength of the study, generated data, codes and categories were controlled by all members of the team (peer check) as well as experts outside the team, who had an experience of qualitative research in the relevant field (external check). To ensure the transferability of data, the participants were selected from different socio-economic levels and from different ethnic groups. The participants were enrolled in the study after obtaining a written informed consent; they were assured that the collected information would remain anonymous and confidential.

\section{Results}

This paper reports the findings of a more comprehensive qualitative study. We studied direct and indirect experiences of 21 people, including 18 women with a history of induced abortion, one expert with 12 years of experience in providing prenatal care at health centers, one midwife with eight years of experience in women's wards, and one women whose sister died due to the complications of induced abortion. The mean age of participants was $29.16 \pm 6.61$ years (with a range of 18-44 years). Most women said that the decision to undergo induced abortion was the most difficult decision in their lives, which had been associated with stress, confusion, and fear. Three participants underwent induced abortion without informing their husbands. This group of women said that the experience of abortion was the worst experience in their lives. In $70 \%$ of cases induced abortion had been performed without notifying husbands. In most cases the abortion was induced via the use of vaginal suppositories and prostaglandin ampoules which had been purchased from pharmacies or midwifery clinics or were provided by midwives and gynecologists. Due to the sensitivity of the issue, and because of the stress and regret of abortion, most of women were very sad and upset when speaking. They were asked the following questions: "What was your expected outcome that motivated you to undergo induced abortion?" or "What outcomes did you expect when you underwent induced abortion?" Based on the collected data, three major themes were extracted from their experiences, which included the following: 1. Expected favorable health-related outcomes of induced abortion, 2. Expected favorable economic outcomes of induced abortion, and 3. Expected favorable outcomes of induced abortion in terms of social and family relationships. Therefore, the studied women underwent induced abortion to achieve these three outcomes. In the following sections (3.1. to 3.3), we present details about each of the extracted themes and subthemes.

\subsection{Expected favorable health-related outcomes of induced abortion}

This theme included two sub-themes: 1) Expected value of induced abortion for preventing the birth of a child with congenital disorders, and 2) Expected value of induced abortion for maintaining and improving the health and beauty of mother.

3.1.1. Expected value of induced abortion for preventing the birth of a child with congenital disorders:

The majority of studied women stated that they underwent abortion because they believed it could prevent the birth of a child with congenital disorders. They expected that the termination of pregnancy could help them to prevent the 
birth of a child with defects caused by maternal age and consanguineous marriage. They also said it could prevent the birth of another child with congenital disorders.

1) Induced abortion in older ages for preventing the birth of a child with congenital disorders:

Induced abortion is sometimes undertaken by older women to prevent the effect of maternal old age on children. One of the participants, working in welfare organization, said: "I was old, and we were cousins. As I was aware of the problems of pregnancy in older ages and the higher risk of having a sick baby due to consanguineous marriage, I felt that I would not have a good pregnancy. Hence, I decided to terminate my pregnancy." (Participant 16, 36 years old).

2) Induced abortion in consanguineous marriages for preventing the birth of a child with congenital disorders: Consanguineous marriage and its possible effects were among women's concerns; according to the participants, women sometimes undergo induced abortion in order to prevent these types of problems. A mother stated that: "Because of the consanguineous marriage we worried about the future of our children. We had fears that our child might have a problem." (Participants 11, 26 years old).

3) Induced abortion for preventing the birth of another child with congenital disorders:

Mothers who previously had a child with congenital disorders underwent induced abortion to prevent the repetition of birth anomalies. One of the mothers said: "I was not upset because of my pregnancy, it was sad that I had a sick kid and I feared to have another sick child. My son was 6 months old when he was born; he was kept in an incubator for one month and 18 days. He was simultaneously affected by renal and digestive illnesses. I was afraid that this one may have similar condition. At that time I was just involved in the treatment of my first child; the abortion could help me to spend more time with my sick child. I did not know what percentage the new baby would be healthy, but I was not able to accept the risk. I asked myself which one is more difficult, having two sick children, or undergoing the difficulties of abortion? "(Participant 1, 32 years old).

3.1.2. Expected value of induced abortion for maintaining and improving the health and beauty of the mother:

We found some sub-themes for the expected value of induced abortion for maintaining and improving the health and beauty of the mother; the sub-themes were as follows: 1) Prevention of the risks associated with short time intervals between pregnancies, 2) Prevention of the exacerbation of maternal diseases, 3) Prevention of pain and complications of labor, and 4) Maintaining beauty and prevention of body deformity.

1) Prevention of the risks associated with short time intervals between pregnancies

In cases where the time interval between two pregnancies was less than two years, mothers expected that the termination of pregnancy could help them to avoid the related complications. An Arabic-speaking participant said: "My children were too young, one of them was four years old, and the other was 1.5 years old. I could not bear the third child so soon...," she continued: "we had a rented house and the costs of life were too much. However, my main reason for undergoing abortion was that my children were too young. I could not bear. I was skinny and anemic. I am still too weak. Because of the pregnancy, me and my husband were too upset and nervous." (Participant 6, 25 years old) Most women with a short time interval between their pregnancies believed that they had become physically weak because of the new pregnancy. They expected that the termination of pregnancy would allow them a chance to spend more time for themselves and their childrens' health. For example, one of the participants, who was the mother of 6-month-old twins said: "I had not yet recovered, however I become pregnant soon after the birth of the twins. At that time, I was breast-feeding the twins and I was forced to stop breastfeeding." Another participant said: "My first baby is still six months old, and I am affected by anemia. At least three years is required to prepare a mother again for having a new child"

2) Prevention of the exacerbation of maternal diseases.

In cases when the maternal morbidity was not medically severe and there was no legal permit for abortion, women terminated their pregnancy based on their own personal decisions. A participant, who was a Behvarz, stated that "Me and my husband decided not be have another children at all, because I have asthma and in my last pregnancy I faced too many difficulties. I decided to undergo abortion because of my disease. In my previous pregnancy, I suffered too much." (Participant 15, 36 years old) Another mother said: "I became pregnant while I was $15 \mathrm{~kg}$ overweight ... My husband was working as an employee, and he had an overweight colleague who became pregnant and consequently suffered from high blood pressure. He was afraid that I might face such a condition. I knew that obesity exacerbated the complications of pregnancy. In addition, the results of BHCG showed that it was high. It was predicted that I might have twins; I knew that such a condition made my condition worse." (Participant 4, 29 years old)

3) Prevention of labor pain and complications of delivery

Some women contributing in our study, reported that they terminated their pregnancy to prevent the problems and consequences of cesarean section. One of the participants said: "I had experienced cesarean section twice. After the second cesarean, I suffered from many problems, both physically and mentally. I was admitted to the Surgery room 
twice. I could not walk, I had a urinary problem. This time, when I saw the result of pregnancy test I was shocked. I was again reminded of all that had happened to me." (Participants 14, 32 years old) Another mother raised her experiences as follows: "I beared all the labor pain, but they said that the condition of the baby is not good. I underwent a cesarean section. It was hard. For a long time I had pain at the suture site. I had back pain; I could not walk. In the last pregnancy, I thought I could not bear all that pain." (Participants 12, 30 years old) Some of the participants also said that they underwent induced abortion due to the fear of vaginal delivery, the expected pain, and suffering, and fear of repeating the unpleasant experience of past pregnancy and childbirth. One of the participants said: "In the previous pregnancy I was on a complete bed rest. Until the fifth month, my mother took care of me. Although I was very willing to have a child, I suffered too much. Even, my mother could no longer help me." Another participant said: "I had a terrible pregnancy craving when I was pregnant. For four months I suffered from nausea and vomiting. I was not able to cook and to eat anything at all. I was hospitalized twice. I was sleeping throughout the first early months." (Participant 5, 30 years old) Another mother said: "In my previous pregnancies, I had a vaginal natural delivery. I had difficulties delivering the child. Maybe, if I had undergone cesarean section delivery, I would not have a fear of delivery. It was implausible for me to handle another pregnancy and childbirth again." (Participant 10, 44 years old) Some of the participants underwent induced abortion to prevent the undesirable effects of pregnancy and delivery, on their mental health. One of them said: "I suffered from postpartum depression after my previous pregnancy. I had strange and eccentric thoughts. I spent too much on treatments and medications." (Participant 14, 32 years old)

4) Maintaining beauty and prevention of body deformity

One of the sub-themes which were found in this study was the concerns of younger participants regarding the physical consequences of pregnancy. Because they feared that the continuation of pregnancy would reduce their bodily beauty, they had terminated the pregnancy to maintain the good shape of their body. One of the participants said: "In my previous pregnancy, I gained $20 \mathrm{~kg}$ of weight. Because of the change in my size, I was not able to wear my previously bought clothes. Whenever I went shopping, I felt depressed, because my new body size was fortyeight. I went to a gym for two years so I could lose weight. I did not want to have the same appearance again." (Participant 7, 28 years old) A midwife stated that: "The viewpoints of women have changed. They do not wish to observe a change in their appearance as a result of pregnancy. For the same reason, many mothers do not breast feed their babies and give various excuses. I knew a lady who was a sports coach; she told me pregnancy made her fat, hence even though it was her first child, she decided to undergo an abortion." (Participant 21, 36 years old).

\subsection{Expected favorable economic outcomes of induced abortion}

This theme was extracted from the experiences of participants separately or together with other themes. This theme included two sub-themes: job preservation and promotion, and prevention of an increase in the cost of living.

3.2.1. Job preservation and promotion.

This sub-theme was extracted from the statements of employed women. They expected that that their pregnancy threatened their daily life and work; hence, they thought that induced abortion could help them to preserve their jobs. One of the participants who had terminated her first pregnancy stated that: "It was two years after marriage, when finally I was hired in a Finance Organization; I was very happy. By continuing pregnancy, I would have missed the opportunity. Now my husband is unemployed and I am in charge of living costs and expenditures. I am satisfied with my life despite this problem. If I had continued the pregnancy, surely I would have not had any other job opportunity. I had been waiting for this opportunity for a couple of years." (Participant 17, 29 years old) Another participant said: "I was recently moved from a district to Ahvaz. I had made many attempts, throughout the year, for the move; I had just obtained a permit to move and I had not moved to the new workplace. I had not introduce myself yet. How could I say I was pregnant? After a month since the day I had started my work, without having to tell anybody that I am pregnant, I underwent abortion." (Participant 5, 30 years old). Another participant said: "Motherhood is a good thing but not for me, as I work until 4 pm every day. All my family was living in another province, we had a rented apartment, and my husband was unemployed. I still wanted life as it was. I wanted to terminate everything soon and I wanted everything to be as it was." (Participant 17, 29 years old).

3.2.2. Prevention of an increase in the costs of living.

A number of women believed that pregnancy and having children could increase the cost of living; hence they had decided to terminate their pregnancies to prevent such costs. For instance, one of the participants said: "I have to spend too much for my twins. My husband is working in a battery store, and he has a very low income, we have a rented apartment (Participant 3,18 years old). One of the participants who had a history of 12 pregnancies and four abortions, including three induced abortions and one spontaneous abortion, said: "After the fourth child I did not want any more children. When you live in a 12-meter room, how could you want a baby? We do not have bread to eat, if I had the three aborted children I think we all would have died of hunger." (Participant 10, 44 years old). A 
public health expert said: "The majority of them have many financial problems and they even borrow money for their daily costs of living. They come to us and cry a lot. They tell us their husbands are unemployed or drug addicts. We have no choice except to give them the address of places where induced abortion is performed in secret." (Participant 20, 38 years old).

\section{3. Expected favorable outcomes of induced abortion in terms of social and family relationships}

This theme had two sub-themes, including the following: expected effects of pregnancy termination on improving family relationships and on prevention of conflicts and disputes in the family, and expected effect of pregnancy termination on improving educational status.

3.3.1. Expected effects of pregnancy termination on improving family relationships and prevention of conflicts and disputes in the family

Some of the women underwent induced abortions in order to prevent divorce and separation. One of them said: "We had a short engagement period, and soon we got married. I was too young. About one or two months after marriage, I found that I was pregnant. Because of the pregnancy we even decided to divorce in the early months of marriage. The family of my husband did not have a good view to this marriage and they even pushed my husband to divorce. I thought that abortion could help me to protect my marriage." (Participant 2, 21 years old) Another participant said: "My husband did not want to have another child. We also had many disputes. First, I thought he may accept the child, but I was wrong. He was extremely nervous. ... finally, I found the address of someone who performed a secret abortion." (Participant 4, 29 years old) One of the women who underwent induced abortion to improve family relationships, said: "When I was pregnant, my husband hurt me a lot. I was fed up. Now I do not like to become pregnant and have a child anymore. But after the abortion, he supported me; he even cried." (Participant 9.32 years old) One of the other participants expressed her experience and said: "Since the time of marriage, my husband had no interest in our life. (When I became pregnant) he was really mad and insulted everything. The abortion helped to keep our problems at the same level, not worsening it." One of the women stated that: "My husband made me jump up the stairs. Sometimes he told me to undergo abortion unless he would kill himself. He made me sit on his motorcycle and go out of the city. He rode the motorcycle on the rocks so that I would abort the baby. I cried so much, but it was not effective. I just suffered all the problems to protect my marriage." (Participant 9, 42 years old). Some of the participants terminated pregnancy to prevent the escalation of family problems. One of them said: "I did not want to exacerbate the family condition at all. My husband is unemployed and on the other hand is suffering from mental and psychological illnesses. Unfortunately, he is a drug addict and now he is in a rehabilitation center. If I wanted to continue the pregnancy, everything would be ruined." (Participant 13, 28 years old). A woman whose sister died of severe bleeding after induced abortion said: "The husband's family did not know they were married. My sister was married in secret. She was older than her husband. Her husband is now in prison; he disagreed with the pregnancy. To keep the story hidden, they asked a midwife to terminate the abortion; the midwife used a knitting mill or something like that. My sister had severe bleeding. We transferred her to a hospital, but she did not receive enough care and she died there (crying)." (Participant 19, 38 years old)

3.3.2. Expected effect of pregnancy termination on improving educational status.

This sub-theme was extracted from the experiences of younger women, especially those who were college students. A large percentage of women married while they were studying and a lot of them decided to continue their education after the marriage. The desire to continue education and to study, was one of the reasons for the termination of pregnancy: "My last child was my son who was 6 years old. My children had grown up and I had more time, hence I decided to continue my education. I decided to start a graduate course. However, this event disappointed me a lot. If I wanted to continue the pregnancy, I had no chance of continuing my education for a long time." (Participant 16, 36 years old) One of the women said in a different statement: "I had a miserable life. I was 13 years old when I married. I could not study at that time. I did not want my kids to be like me. I always underestimated my capacities; however, I could have been better than this. My children could be better than this (crying). I was bothered a lot and my children were too young. However, I did not undergo abortion because of my problems; I performed abortion just because I had concern for them. They will thank me in the other world." (Participant 10, 44 years old)

\section{Discussion}

In this study, which aimed to investigate the outcomes of induced abortion expected by women, three major themes were extracted. The results showed that the studied women underwent induced abortion to achieve their favorable social, economic, and health outcomes. According to some theories and models of behavior, including the theory of expected value, people's expected outcomes of a behavior can encourage or discourage them to adopt that behavior $(23,24)$. In addition, as denoted in the theory of reasoned action and the theory of planned behavior, Ajzen and 
Fishbein argue that behavioral beliefs include people's expected outcome of their behaviors and thus they can influence a person's attitude towards the adoption or non-adoption of a specific behavior. According to their views, these beliefs are an important part of people's attitude toward a behavior they are going to undertake (25). Schaster believes that women, unlike their value statements which are the result of their defense mechanisms, when faced with the real situation and experience an unwanted pregnancy, will behave according to their true attitudes. (26). One of the expected outcomes of women undergoing induced abortions, was maintaining and improving their health. According to the results of many studies, maintaining the physical and psychological health of mothers is a reason for undergoing induced abortions. Fear of childbirth and its complications (28), fatigue and burnout (28), and being old (29) were the major causes of maternal concern. In this study, there were some traces of such factors among the studied women. One of the other reasons for induced abortion was women's concerns to prevent the birth of a sick baby. The mother's age at the time of pregnancy was an important reason for this concern. The results of some studies have shown that per every year of increase in a woman's age, the odds ratio of the decision to perform an abortion increases by 0.08 . According to Erfani (2010), the age of around 35 years is associated with the highest risk of abortion (30). In line with this finding, Nikpour et al. (2012) showed that $40.6 \%$ of induced abortions in women referred to hospitals in the south of Tehran, occurred at the age of over 36 years (16). In addition, in Fisher's study, with increasing the age of mothers, the risk of induced abortion increased too (8). Usually women bear their wanted children at a young age; in addition, with increasing women's age, their experience and knowledge of abortion and its methods increases. Age is not only a factor affecting the abortion, but also a strong predictor of repeated cases of induced abortion. In other words, young women who had experienced induced abortions once are more at risk of repeat abortion. In this context it has been argued that the attitude and behavior towards abortion are formed and become internal at a young age. During the reproductive age, women remain stable (31). Consanguineous marriage was another factor that influenced women to undergo abortion in order to prevent congenital anomaly. Consanguineous marriage is common in our country, although its prevalence has been reported differently in different regions. A study on more than 300 Iranian couples showed that about $38 \%$ of marriages in the country were consanguineous marriages, and about a third of them occur between cousins. This type of marriage is common and even has become more prevalent due to different social and cultural factors; for instance, people believe that consanguineous marriage results in a family's stability and has several socio-economic benefits (32). The short time interval between pregnancies was also another factor that encouraged mothers to undergo abortion to maintain their health. Vaisi and Zangeneh (2012) conducted a quantitative study in Kermanshah and showed that the reluctance to have more children and the short time interval between pregnancies were the most important causes of illegal abortion in women in Kermanshah (33). According to the results of a study by Mortazavi, due to the short time interval between the pregnancies, women may not be physically ready for a new pregnancy (34). In our study, participants reported that the time interval between pregnancies is an opportunity to recover and become ready again. Zamani et al. (2013) conducted a qualitative study and showed that lack of preparation and perceived weaknesses were among the main causes of unwanted pregnancy (35). In another study, the researchers found that the self-efficacy score of women with a history of unwanted pregnancy was lower than other women. The difference in the scores was attributed to their low levels of tolerance of pregnancy and delivery problems (36). Maternal illness was one of the leading causes driving women to pregnancy termination. This finding is consistent with the results of other studies in other countries and also the results of Mortazavi et al.'s study (34, 37-38).

The second major theme in our study was the expected favorable economic outcomes resulting from the termination of pregnancy. Some of the participants believed that pregnancy could threaten their job position. On the other hand, a large number of the participants said that they underwent induced abortion to prevent the extra costs of living. Brown, in his study, highlighted the role of economic factors which motivate people to undergo abortion (28). Based on the results of a study by Visaria et al., poverty was one of the incentives to terminate a pregnancy (38). It seems that in recent years the role of economic factors on reproductive behavior have become more significant. Of the 11 major causes of induced abortions in America, economic issue was the leading cause of abortion (39). In addition, Santeill et al. reported that the economic problems were the major and primary cause of induced abortion in $48.2 \%$ of cases (29). In this study, many of the concepts and beliefs were shaped under the influence of financial problems. In all cases, where more than one factor led to the abortion, the participants reported financial problems as one of the main factors leading to induced abortion. According to the theory proposed by Harvey Leibeshtiene, reproductive behavior in every community is under the influence of a rational economic behavior. According to this theory, economic profit or non-profit are the factors that lead the parents to decide how many children to have. Couples assess the costs and expenses of their children and accordingly decide on the number of children (40). 
The third major theme of the study was the expected favorable outcomes of induced abortion in terms of social and family relationships. A number of participants believed that the continuation of pregnancy would affect their daily lives and interfere with many programs, such as family relations, taking care of other children, employment, and education. In addition, according to the results of this study, women believed that continuation of pregnancy would lead to many complications in their life, which prevented them to fulfill their own and their children's needs. Finer et al. reported that the major changes in women's lives (with reference to education and occupation) were one of three important factors motivating women to undergo abortion (41). Bigese et al. say that some women think having a child could have a negative impact on their life as it has an interference with work and education (39). In some studies, this theme is entitled as the "wrong time", which exacerbates women's mental readiness; it is due to women's reluctance to disrupt their education and life programs. Improving family relationships, especially relationship with the husband, was one of the motives of the participants to undergo induced abortion and pregnancy termination. Some studies have highlighted the role of spouse or sexual partner (as an intra-individual factor) in making decisions and taking action to undergo induced abortion. According to Brown (2005), the most important causes for induced abortion are as follows: husbands or sexual partners insist on having induced abortion, occupational concerns, education level of the mother, and having the desired number of children (28). In a study on American women, $31 \%$ of cases of induced abortion were due to factors related to the sexual partner (39). Insufficient support from the husband, husband's lack of employment, addiction, and family disputes are reported as the most important factors related to the husband. Although most cases of abortion can be attributed to one of the three themes mentioned above, more than half of the participants introduced a number of other factors as well. Finer et al. (2005) also showed overlapping causes of abortion, especially in terms of financial resources (41). Nevertheless, the combination of these factors in different populations, including the population under study, is unique and different.

As one of the limitations of this study, women who declined to be interviewed may have different experiences than women who volunteered to participate in the study. In addition, due to the illegal nature of induced abortions in Iran, many experts did not consent to take part in the study because they had concerns about the legal aspects of this topic. In addition, in this study we did not investigate the motives of induced abortion from the viewpoints of husbands whose wives underwent an induced abortion.

\section{Conclusions}

The findings of this study indicate that a number of complex and interrelated factors may motivate a person to undergo induced abortion. Hence, it is necessary to take intervention measures for various aspects of the phenomenon so as to prevent induced abortion and its related complications. Hence, it is recommended to provide women with counseling interventions affecting behavioral beliefs.

\section{Acknowledgments:}

This study was funded by Social Determinants of the Health Research Center in Jondishapur University of Medical Sciences, Ahvaz (Project Number and Ethics Code: SDH-9101; Eth-683). The research team hereby thanks all participants in the study and appreciates the Deputy of Research and Technology of Ahvaz Jondishapur University of Medical Sciences for their valuable contribution.

\section{Conflict of Interest:}

There is no conflict of interest to be declared.

\section{Authors' contributions:}

All authors contributed to this project and article equally. All authors read and approved the final manuscript.

\section{References:}

1) Herold S. The new public face of abortion: connecting the dots between abortion stories. RH Reality Check. 2012. Available From: http://rhrealitycheck.org/article/2012/07/08/new-public-face-abortionconnecting-dots-between-abortion-stories

2) Sedgh G, Henshaw S, Singh S, Ahman E, Shah IH. Induced abortion: estimated rates and trends worldwide. The Lancet. 2007; 370(9595): 1338-45. doi: 10.1016/S0140-6736(07)61575-X.

3) Shah I, Ahman E. Unsafe abortion in 2008: global and regional levels and trends. Reprod Health Matters. 2010; 18(36): 90-101. doi: 10.1016/S0968-8080(10)36537-2. PMID: 21111353. 
4) World Health Organization. The prevention and management of unsafe abortion. WHO/MSM/92.5.Geneva: WHO; 1992.

5) Rasch V, Muhammad H, Urassa E, Bergstrom S. The problem of illegally induced abortion: results from a hospital-based study conducted a district level in Dares Salaam. Trop Med Int Health. 2000; 5(7): 495-502. doi: 10.1046/j.1365-3156.2000.00584.x. PMID: 10964272.

6) Shahbazi SH, Fathizadeh N, Taleghani F. The process of illegal abortion: a qualitative study. Payesh. 2011; 109(2): 183-95.

7) Studing unsafe abortion: A practical guide. Geneva, World Health Organization. 1996.

8) Fisher WA, Singh SS, Shuper PA, Carey M, Otchet F, MacLean-Brine D, et al. Characteristics of women undergoing repeat induced abortion. Canadian Medical Association Journal. 2005; 172(5): 637-41. doi: 10.1503/cmaj.1040341.

9) Gissler M, Karalis E, Ulander VM. Decreased suicide rate after induced abortion, after the Current Care Guidelines in Finland 1987-2012. Scand J Public Health. 2015; 43(1): 99-101. doi: 10.1177/1403494814560844. PMID: 25420710.

10) Elul B, Bracken H, Verma Sh, Ved R, Lockwood K. Unwanted pregnancy and induced abortion in Rajashtan, India: a qualitative exploration. New Delhi, India, Population Council, New Delhi; 2004 (At: www.popcouncil.org/pdfs/SAReport.pdf.

11) Milsom I. Contraception and family planning. European practice in Gynecology and Obstetrics Series. 1st ed. Elsevier. Sweden. 2006.

12) Erfani A, Kazemipour S. The incidence of induced abortion in Tehran: the role of contraceptive failures. Journal of Population Association of Iran. 2012; 8: 63-84.

13) Aghayari T, Mehryar AH. Estimation of induced abortion rates in Iran: application of proximate determinants model. Journal of Population Association of Iran. 2007; 2(3): 1-10.

14) Erfani A, Mcquilan K. Rtes of induced Abortion in Iran: The roles of contraceptive use and religiosity. Stud Fam Plann. 2008; 39(2): 111-22. doi: 10.1111/j.1728-4465.2008.00158.x. PMID: 18678175.

15) Majlessi F, Rahimi Forooshani A, Shariat M. Prevalence of induced abortion and associated complications in women attending hospitals in Isfahan. East Mediterr Health J. 2008; 14(1): 103-9. PMID: 18557457.

16) Nikpour B, Majlessi F, Tol A, Eshraghi N. Assessment of induced abortions and its effective factors in comparison with spontaneous abortions among women refer to hospitals in south of Tehran. Journal of Health Breeze Family Health. 2013; 1(3): 14-20.

17) Okonofua F, Omo-Aghoja L, Bello Z, Osughe M, Agholor K. Self-reporting of induced abortion by women attending prenatal clinics in urban Nigeria. Int $\mathrm{J}$ of Gynecol Obstet. 2010; 111(2): 122-5. doi: 10.1016/j.ijgo.2010.05.020. PMID: 20887990.

18) Ajzen I, Madden T. Prediction of goal-directed behavior: attitudes, intentions, health, university and perceived behavioral control. Journal of Experimental Social Psychiatry. 1986; 22: 453-74.

19) Singh BK, Williams JS. Attitudes and behavioral intentions about abortion. Population and Environment. 1983; 6(2): 84-95.

20) Ajzen I, Fishbein M. Attitude-behavior relations: a theoretical analysis and review of empirical research. Psychological Bulletin. 1980; 84(5): 888-918. doi: 10.1016/0022-1031(86)90045-4.

21) Forensic Medicine Organization. Growth of 14 percent in Licensing of therapeutic abortion in the country. 2015. Available from: http://www.farsnews.com/newstext.php?nn=13940123001182

22) Polit DF, Beck CT. Nursing Research: principle and methods. Lippincott Williams \& Wilkins. Philadelphia. PA. USA. 7th ed. 2003; 305-8

23) French DP, Hankins M. The expectancy-value muddle in the theory of planned behaviour and some proposed solutions. Br J Health Psychol. 2003; 8(1): 37-55. doi: 10.1348/135910703762879192.

24) Cronen VE, Conville RL. Fishbein's conception of belief strength: a theoretical, methodological, and experimental critique. Speech Monogr. 1975; 42(2): 143-50. doi: 10.1080/03637757509375888.

25) Fishbein M, Ajzen I. Belief, attitude, intention, and behavior: an introduction to theory and research. Reading, Mass: Addison-Wesley Pub. 1975.

26) Schaster S. Abortion in moral world of the Cameroon gradsfields Reprod Health Matters. 2005; 13(26): 130-8. doi: 10.1016/S0968-8080(05)26216-X.

27) Larsson M, Aneblom G, Odlind V, Tyden T. Reasons for pregnancy termination, contraceptive habits and contraceptive failure among Sedish women requesting an early pregnancy termination. Acta Obstet Gynecol Scand. 2002; 81(1): 64-71. doi: 10.1046/j.0001-6349.2001.00169.x. PMID: 11942890. 
28) Broen AN, Moum T, Bodtker AS, Ekeberg O. Reasons for induced abortion and their relation to women's emotional distress: a prospective, two-year follow-up study. Gen Hosp Psychiatry. 2005; 27(1): 36-43. doi: 10.1016/j.genhosppsych.2004.09.009. PMID: 15694217.

29) Santelli JS, Speizer IS, Avery A, Kendall C. An exploration of the dimensions of pregnancy intentions among women choosing to terminate pregnancy or initiate prenatal care in New Orlean, Louisiana. Am J Pub Health. 2006; 96: 2009-15. doi: 10.2105/AJPH.2005.064584. PMCID: PMC1751822.

30) Erfani A. Tehran survey of fertility. A study on the reproductive behavior of married women in Tehran. Tehran: The population studies and research center in Asia and pacific (PSRC). 2010.

31) Heikinheimo O, Gissler M, Suhonen S. Age, parity, history of abortion and contraceptive choices affect the risk of repeat abortion. Contraception. 2008; 78(2): 149-54. doi: 10.1016/j.contraception.2008.03.013 PMID: 18672117.

32) Saddat M, Ansari-Lari M, Farhud DD. Consanguineous marriage in Iran. Ann Hum Biol. 2004; $31(2)$ : 263 9. doi: 10.1080/03014460310001652211. PMID: 15204368.

33) Veisi F, Zanganeh M. The Causes of Illegal Abortions and Their Methods in Outpatient Clinics of Kermanshah University of Medical Sciences. IJFM. 2012; 18(1): 47-52.

34) Mortazavi F, Motaghi Z, Shariati M, Damghanian M. Women's experience of unwanted pregnancy: A qualitative study. Journal of Kermanshah University of Medical Sciences. 2013; 15(6): 492-505.

35) Kheiriat M, Zamani Alavijeh F. Araban M. Exploration into causes of unwanted pregnancy: A qualitative study. Journal of Evidence-based Care. 2014; 4(1): 41-52.

36) Zamani Alavijeh F, Nouhjah S, Kheiriat M, Haghighzadeh MH. Related factors of unwanted pregnancy and intention of women to continue or terminate pregnancy based on health belief model. Payesh. 2012; 11(6): 877-85.

37) Motaghi Z, Keramat A, Shariati M, Yunesian M. Triangular Assessment of the Etiology of Induced Abortion in Iran: A Qualitative Study. Iran Red Crescent Med J. 2013; 15(11): 9442. doi: 10.5812/ircmj.9442. PMID: 24719694, PMCID: PMC3971786.

38) Visaria L, Ramachandran V, Ganatra B, Kalyanwala S. Abortion in India: emerging issues from qualitative studies. Econ Polit Wkly. 2004: 5044-52.

39) Biggs AM, Gould H, Greene Foster D. Understanding why women seek abortions in the US. BMC Womens Health. 2013; 13: 29. doi: 10.1186/1472-6874-13-29.

40) Hosseini H. Introduction to economic demography- population and family planning. Hamedan: Bu-AliSina University; 2002.

41) Finer LB, Frohwirth LF, Dauphinee Susheela Singh LA, Moore AM. Reasons U.S. women have abortions: quantitative and qualitative perspectives. Perspect Sex Reprod Health. 2005; 37(3): 110-8. doi: 10.1111/j.1931-2393.2005.tb00045.x. 